\title{
The Utility of a Standardized Evaluation Form for Complaints in Patients with Acute Abdominal and Flank Pain
}

\author{
Bedia Gülen', Cem Oktay², Güleser Akpınar², Ertan Sönmez ${ }^{1}$ \\ 'Department of Emergency Medicine, Bezmialem Vakıf University School of Medicine, İstanbul, Turkey \\ 2Department of Emergency Medicine, Akdeniz University School of Medicine, Antalya, Turkey \\ ${ }^{3} \mathrm{Clinic}$ of Emergency Medicine, Şişli Hamidiye Etfal Training and Research Hospital, İstanbul, Turkey
}

\begin{abstract}
Aim: In this study, we aimed to assess the diagnostic accuracy and cost effectiveness of a first-step evaluation form, which we improved for patients administrated to the emergency department (ED) with non-traumatic acute abdominal and flank pain.

Materials and Methods: Patients presenting with non-traumatic acute abdominal and flank pain complaints to the ED were included in this prospective cross-sectional cohort study in two consecutive months. Control group patients were evaluated with forms currently in use in our ED in the first month, whereas the evaluation of the test group was perfromed with the standardized evaluation form specifically designed for acute abdominal and flank pain in the second month.

Results: Throughout both sessions, 1224 patients in total presented with non-traumatic abdominal and flank pain. Out of these, 285 of those enrolled in the first session, and 335 enrolled in the second session. Both control and test groups, which were similar demographically and with respect to vital symptoms/ findings, did not show any significant difference with respect to the examination/test and treatment. However, we observed a significant decrease in ED patient care expenses in the group evaluated with the new standardized form. Among them, those who were evaluated with the standardized form had relatively fewer complaints than those evaluated with the currently available evaluation form.

Conclusion: Our results showed that utilization of a new standardized form for patients presenting with non-traumatic acute abdominal and flank pain significantly decreased patient care expenses for ED care; furthermore, they experienced relatively fewer complaints after discharge from the ED. (Eurasian J Emerg Med 2016; 15: 20-3)
\end{abstract}

Keywords: Abdominal pain, flank, cost, standardized form, emergency department

\section{Introduction}

Acute abdominal pain is defined as an abdominal pain persistent for less than a week. Non-traumatic acute abdominal or flank pain is one of the major reasons for emergency department (ED) visits and accounts for approximately $5 \%-10 \%$ of all ED visits (1-3). However, the rate of undefined abdominal pain is reported to be $41 \%$ (4). The elderly account for $20 \%$ of ED visits, of which $3 \%-4 \%$ are for acute abdominal pain. Therefore, the approach to acute abdominal pain requires a fast and precise diagnosis in addition to appropriate triage and care.

Taking into account that noting down the history and performing physical examination takes $90 \%-95 \%$ of the patient evaluation time, a standardized method to perform this evaluation may increase the speed of care (5).
The purpose of this study was to evaluate the effectiveness of the use of a standardized complaint evaluation form developed for patients admitted to the ED of a university hospital for non-traumatic abdominal pain and flank pain on diagnostic accuracy and speed as well as on patient care costs.

\section{Materials and Methods}

This prospective cross-sectional cohort study was conducted at the ED of a University Hospital. Informed consent was obtained from all participants, and the study was monitored by the local ethical committee of Akdeniz University. Inclusion criteria included patients aged 18 years and above and admitted to the ED of University Hospital for non-traumatic acute abdominal pain. Persons with traumatic abdominal and flank pains, persons aged under 18 , persons with 
chronic abdominal and flank pain (abdominal and flank pain complaint persistent for more than 1 week), patients whose history could not be taken due to change of consciousness, and women with third trimester pregnancy were excluded.

The study data were collected within two periods separately. Each period consisted of one month. In the first period of the study (Group 1), patients admitted for abdominal/flank pain were given the ED Patient Evaluation Form, which was already routinely used by triage staff, and also the form entitled "Study on Patients admitted to the ED for Non-traumatic Acute Abdominal and Flank Pain."The assistant doctor who evaluated the patient was asked to fill in the form. In the second period of the study (Group 2), patients admitted for non-traumatic abdominal and flank pain were given the "standardized complaint evaluation form" by the triage staff, and the doctors were informed that they should only use this form for these patients. All doctors in charge of the ED were given a 30-min briefing on how to fill in the form and about the contents of the form.

All patients included in the study in both of these periods were called by telephone approximately 15 days after admission. The patients were asked whether their complaint persisted, and if the complaint disappeared, when it disappeared; whether they had visited another medical institution in 10 days (ED or out-patient clinic), and if they did, whether any additional test or treatment was performed; or whether any surgical intervention or fatality occurred. The patients were called by the evaluating doctors who were not aware of the diagnosis and outcome of the patients between the $15^{\text {th }}$ and $25^{\text {th }}$ days after the discharge.

The hospital cost data for all the patients included in the study that occurred during the ED visits were obtained retrospectively from the MediHasta ${ }^{\circledR}$ software used at our hospital.

\section{Statistical analysis}

The data obtained were recorded in the Statistical Package for the Social Sciences 15.0 for Windows (SPSS Inc; Chicago, IL, USA) software and statistical analyses were performed. While continuous variables were expressed as the mean \pm SD and median (min.-max.), frequency data were expressed as percentages. In comparison of the two cohorts, the Mann-Whitney $U$ test was used for data that was continuous, but did not match normal distribution, and for ordinal data, whereas the chi-square test was used for frequency data. The normal distribution was examined with the Kolmogorow-Smirnov test. All the hypotheses were formed bi-directionally, and the alpha significance value was taken as 0.05 .

\section{Results}

In the first and second periods of the study, 378 and 474 patients were included, respectively. Overall, 232 of the total 852 patients were excluded from the study due to the exclusion criteria. Data were evaluated over 285 patients for the first period and over 335 patients for the second period.

The mean age of patients evaluated was $39.9 \pm 15.4$ years, and 242 of them (39\%) were male. Overall, 438 (70.6\%) patients had abdominal pain, whereas 182 patients (29\%) had flank pain. Table 1 shows the patients' demographics and pain type and severity.

The tests required by the doctors were compared between the period in which the form was not used and the period in which the form was used. It was determined that the decision of the doctors to require tests did not change with the use of the standardized complaint form (Table 2).

The diagnoses of the patients at discharge from the ED were classified. Although the abdominal pain rate was $28.1 \%$ in the group in which the form was not used, the rate was $27.8 \%$ in the group in which the form was used. It was determined that the rate of diagnosing an undefined abdominal pain did not statistically change with the use of the standardized evaluation form $(p=1.000)$.

In this study, $84.9 \%$ and $87.8 \%$ of the patients in Groups 1 and 2 were discharged, respectively. There was no significant difference between the groups in terms of discharge and hospitalization ( $p$ values of 0.706 and 0.820 , respectively) (Table 3 ).

The mean length of stay at the ED for all the patients included in the study was 156 $\pm 116 \mathrm{~min}$ (minimum: $15 \mathrm{~min}$, maximum: $799 \mathrm{~min}$ ). Although the average length of stay was $162 \mathrm{~min}$ in the group in which the form was not used, the average length of stay was $152 \mathrm{~min}$ in the group in which the form was used. There was no statistically significant difference between the groups in terms of the length of stay at the ED $(p=0.559)$.

The costs that arose during the ED evaluations of the patients were compared between the patients in Groups 1 and 2. After the discharge, surgical treatment was needed more commonly in Group 1 (Table 4).

Table 1. Demographics characteristics and pain type and severity of patients with abdominal and flank pain

\begin{tabular}{|l|c|c|c|}
\hline Demographics & Group 1 & Group 2 & p \\
\hline Age Mean \pm SD & $41.1 \pm 15.7$ & $38.9 \pm 15.1$ & 0.087 \\
\hline Median & 38 & 37 & \\
\hline Min-Max & $18-84$ & $18-86$ & \\
\hline Gender (M/F) no & $104 / 181$ & $138 / 197$ & 0.248 \\
\hline Abd/flank pain no & $206 / 79$ & $232 / 100$ & 0.427 \\
\hline Pain severity & 6.57 & 6.69 & 0.554 \\
\hline M: male; F: female & & \\
\hline
\end{tabular}

Table 2. Required tests for the evaluation of patients admitted to the ED for a complaint of abdominal or flank pain

\begin{tabular}{|l|c|c|c|}
\hline Tests & Group 1 & Group 2 & p \\
\hline Complete blood count & 128 & 135 & 0.255 \\
\hline Biochemical tests & 110 & 121 & 0.560 \\
\hline Urinalyses & 161 & 176 & 0.333 \\
\hline Stool examination & 16 & 14 & 0.455 \\
\hline Electrocardiography & 48 & 68 & 0.302 \\
\hline Arterial blood gas & 7 & 4 & 0.361 \\
\hline Chest X-ray & 38 & 34 & 0.258 \\
\hline Plain Abd. X-ray & 38 & 40 & 0.628 \\
\hline Ultrasonography & 67 & 58 & 0.057 \\
\hline Doppler USG & 3 & 5 & 0.732 \\
\hline Abdominal CT & 4 & 5 & 1.000 \\
\hline Other & 19 & 31 & 0.300 \\
\hline
\end{tabular}

Abd: abdomen; USG: ultrasonography; CT: computer tomography 
Table 3. Results of the evaluation of patients admitted to the ED for an abdominal or flank pain complaint

\begin{tabular}{|l|c|c|}
\hline Conclusion & $\begin{array}{c}\text { Group 1 } \\
\mathbf{n}(\%)\end{array}$ & $\begin{array}{c}\text { Group 2 } \\
\mathbf{n}(\%)\end{array}$ \\
\hline Discharge & $242(84.9)$ & $294(87.8)$ \\
\hline Hospitalization & $35(12.3)$ & $33(9.8)$ \\
\hline Transfers & $1(0.4)$ & $1(0.3)$ \\
\hline Refusal to treatment & $7(2.5)$ & $6(1.8)$ \\
\hline To leave the hospital without permission & 0 & $1(0.3)$ \\
\hline Totality & 285 & 335 \\
\hline
\end{tabular}

Table 4. Telephone follow-up of patients on days 15-25 after discharge from the ED

\begin{tabular}{|l|c|c|c|}
\hline Conclusion & Group 1 n (\%) & Group 2 n (\%) & p \\
\hline Continue of complaint & $68(39.1)$ & $40(18.1)$ & $<0.001$ \\
\hline Extra application & $67(38.5)$ & $53(24.0)$ & 0.002 \\
\hline Recurrent application & $44(65.8)$ & $45(84.9)$ & 0.021 \\
\hline Supplement test & $55(82.1)$ & $41(77.4)$ & 0.647 \\
\hline Operation & $9(5.2)$ & $3(1.4)$ & 0.038 \\
\hline
\end{tabular}

The average bill amounts for the patients in Group 2 and Group 1 were $\$ 54.45$ and $\$ 65.41$, respectively. This difference was shown to be statistically significantly $(p=0.002)$.

When the patient complaints were divided into abdominal pain and flank pain, the average cost for patients with abdominal pain was $\$ 68.8$ in the group in which the form was not used and \$58.5 in the group in which the form was used $(p=0.035)$. For the flank pain complaint, these values were $\$ 56.5$ and $\$ 42.5$, respectively $(p=0.030)$.

There was again a significant difference between the groups in terms of cost when the patients were classified as patients diagnosed with undefined abdominal pain complaint and patients with any diagnosis.The average cost of patients diagnosed with undefined abdominal pain complaint was \$70.7 in Group 1 and \$58.1 in Group 2 $(p=0.046)$. The costs for the group with any diagnosis were found to be $\$ 63.4$ (Group 1) and $\$ 53.0$ (Group 2) ( $p=0.024)$.

In this study, 395 of the 536 patients discharged from the ED were reached by telephone (73.7\%); 174 of the 242 patients $(71.9 \%)$ in the group in which the form was not used and 221 of the 294 (75.2\%) of the patients in the group in which the form was used were reached by telephone. These telephone calls were made between the $15^{\text {th }}$ and $25^{\text {th }}$ days after discharge.

\section{Discussion}

Acute undefined abdominal pain is an abdominal pain complaint persistent for less than 7 days and which cannot be defined by physical examination and basic researches. Undefined abdominal pain is a common cause of hospitalization (6). More than $40 \%$ of patients with abdominal pain complaint are discharged from the ED without a diagnosis, whereas more than $35 \%$ are hospitalized, and approximately $56 \%$ are misdiagnosed $(7,8)$.

Lukens et al. (9) reported that $57 \%$ of the patients discharged with undefined abdominal pain diagnosis recovered in 2-3 days after their first visit to the ED. Shesser et al. (10) reported that $82 \%$ of the patients discharged from the ED recovered in 2-3 days. Similar results were obtained in our study. These three studies indicate that the first 2-3 days are considerably valuable for following up patients discharged from the ED with undefined abdominal pain complaint and that complaints that persist after the 3rd day justify further evaluation.

There is not yet a sufficient guide in the literature for evidence-based diagnostic imaging options for patients admitted to the ED for abdominal pain.The present diagnostic studies show that the approaches to abdominal pain diagnosis vary considerably between hospitals. Indications for the use of abdominal X-ray, USG, and CT are variable. Compared to the last century, there is a significant increase in the use of CT for patients with abdominal pain complaint. However, new questions have been raised, such as the increase in costs, unnecessary test requests, or failure to request tests despite the existence of an indication (11). In a study where the contribution of helical CT to acute abdominal pain diagnosis was evaluated, it was shown that mortality decreased and the length of stay at the hospital shortened with the use of helical CT. It was also reported that helical CT was beneficial in diagnosing unforeseeable conditions and potentially serious complications (12). In light of these contributions, the frequency of use of $\mathrm{CT}$ for patients with undefined abdominal pain complaint should be increased.

Although the requests for tests did not differ between groups in our study, the most required tests included whole blood count, biochemical tests, urinalyses, and USG, respectively. It is remarkable that abdominal $\mathrm{X}$-rays are less preferred by doctors due to poor diagnostic sensitivity and specificity. However, in our study, we noted that CT requests were quite low in the $\mathrm{ED}$. With $\mathrm{CT}$ to be required for selected patient groups, re-visits and treatments could be prevented. It should be ascertained for which patients among those who visit the ED for acute abdominal pain that $\mathrm{CT}$ is necessary. However, current test options should be selected according to evidence-based pre-determined diagnosis strategies and the patient profile. Despite the performance of numerous and various tests, one quarter of patients are discharged with undefined abdominal pain diagnosis. At this stage, what are the safe discharge criteria should be the question that must be raised. Doctors are inclined to ambulatory follow-up patients due to limited bed capacity at the hospital. In case the complaint persists, the patient may require a re-visit. Is discharge a safe option in undefined acute abdominal pain? Weiner et al. (13) measured the post-discharge follow-up frequency and duration of complaint for patients visiting the ED for abdominal and flank pain complaints. They called all patients in 2-3 weeks after discharge, but could reach only $70 \%$ of the patients. They found the median pain duration was 3 days as from the ED visit. In conclusion, they reported that patients with non-traumatic abdominal and flank pain could recover in a few days. In a prospective randomized clinic study, Onur et al. (14) researched whether there was any difference in terms of cost and patient safety between observation at the ED and post-discharge follow-up of patients diagnosed with undefined abdominal pain. In conclusion, they proposed that patients with abdominal pain not considered to be life-threatening could be safely discharged home.

The fact that patients desire to use EDs more intensively to receive medical care leads to crowding and delayed care at EDs (15). Several studies have been designed recently in order to reduce crowding in EDs and to raise the speed of care without compromising quality $(16,17)$. These studies aim to find out how delays can be prevented. In our study, we determined that the evaluation form developed for abdominal pain complaint did not reduce the length of 
stay at the ED compared to the classical manually-completed patient evaluation form. The cause of why this duration did not change may be that they do not only measure the patient evaluation duration.

Guerlain et al. (4) researched the effect of a standardized form on the physical examination and diagnosis of patients admitted to the ED for abdominal pain complaint. They stated that patients with acute abdominal pain were evaluated in an irregular and non-standard manner even within the same institution, and inquired whether a standardized form for abdominal pain would increase the quality and quantity of data collected or not. They showed that the abdominal pain form resulted in a significant increase in the recording of information related to complaint history, background and social history, system review, and physical examination. The form was also beneficial in the long-run for retrospective data analysis.

In the literature, there is no sufficient data about the usefulness of standardized forms in terms of accuracy and the early diagnosis of abdominal pain. It was reported that noting down the history and performing physical examination with a standard data collection method increased the diagnostic accuracy of appendicitis in the ED (18). Korner et al. (19) reported that diagnostic accuracy increased by $5 \%$ with structured data records and that the rate of increase in women aged $13-40$ years was $13 \%$. In that society-based study, they reported that diagnostic accuracy improved in patients operated on for the suspicion of appendicitis. In our study, it was researched whether a standardized complaint evaluation form would increase the diagnostic accuracy of abdominal pain and the quality of care or not, but no differences could be found in terms of these criteria.

In a study using T-system ${ }^{\circledR}$ in primary care, Mulvehill et al. (20) researched whether the cost would change and reported that the use of a structured form resulted in a significant increase in cost. In our study, however, we determined that the use of a standardized form reduced ED costs. Although there is no difference between the two groups in terms of test and consultation requirement and the result of the care, the difference in cost may be attributed to the existence of several causes in the etiology of abdominal pain, important differences between diagnostic practices of doctors as a whole, and/or the wide distribution of costs. A cost analysis with much more specific diagnoses and between groups with more patients would be appropriate.

\section{Conclusion}

The use of a standardized evaluation form for abdominal and flank pain does not change the occurrence of complications, such as urgent surgery or the death of discharged patients due to omitted diagnosis, or the length of stay of the patients at the ED; however, the use of standardized forms may reduce the costs for dealing with patients with abdominal pain.

Ethics Committee Approval: The consent of the General Ethical Board of the Akdeniz University School of Medicine was obtained prior to the study.

Informed Consent: Informed consent was obtained from patients.

Peer-review: Externally peer-reviewed.

Conflict of Interest: The authors declared no conflict of interest.

Financial Disclosure: The authors declared that this study has received no financial support.

\section{References}

1. O'Brien MC. Acute abdominal pain. In: Tintinalli JE, Kelen GD, Stapczynski JS, editors. Emergency Medicine: A Comprehensive Study Guide. 7th ed. New York: McGraw Hill; 2010.p.1233-42.

2. Kariman H, Shojaee M, Sabzghabaei A, Khatamian R, Derakhshanfar H, Hatamabadi $H$. Evaluation of the Alvarado score in acuteabdominal pain. Ulus Travma Acil Cerrahi Derg 2014; 20: 86-90. [CrossRef]

3. Gunaydın GP, Dogan NO, Cevik Y, Kormaz H, Savrun A, Cıkrıkcı G. Evaluation of Patients with Renal Colic that Present to an Emergency Department During the Month of Ramadan. Eurasian J Emerg Med 2013; 12: 24-6.

4. Guerlain S, LeBeau K, Thompson M, Donnelly C, McClelland H, Syverud S, et al. The effect of a standardized data collection form on the examination and diagnosis of patiens with abdominal pain. Proceeding of the Human Factors and Ergonomics Society 45th Annual Meeting 2001.p.1284-8.

5. Gross $\mathrm{H}$. Evaluation of abdominal pain in the emergency department. FACEP. 2008, Sep. Avaible from: URL: http://www.augusta.edu/mcg/clerkships/em/documents/evalabdominalpain.pdf

6. Morino M, Pellegrino L, Castagna E, Farinella E, Mao P. Acute nonspecific abdominal pain: A randomized, controlled trial comparing early laparoscopy versus clinical observation. Ann Surg 2006; 244: 881-6. [CrossRef]

7. Irvin TT. Abdominal pain: a surgical audit of 1190 emergency admissions. Br J Surg 1989; 76: 1121-5. [CrossRef]

8. Adams ID, Chan M, Clifford PC, Cooke WM, Dallos V, deDombal FT, et al. Computer aided diagnosis of acute abdominal pain: a multicentre study. Br Med J 1986; 293: 800-4. [CrossRef]

9. Lukens TW, Emerman C, Effron D. The natural history and clinical findings in undifferentiated abdominal pain. Ann Emerg Med 1993; 22: 690-6. [CrossRef]

10. Shesser R, Smith M, Adams S, Walls R, Paxton M. The effectiveness of an organized emergency department follow-up system. Ann Emerg Med 1986; 15: 911-5. [CrossRef]

11. Lee SL, Walsh AJ, Ho HS. Computed tomography and ultrasonography do not improve and may delay the diagnosis and treatment of acute appendicitis.. Arch Surg 2001; 136: 556-62. [CrossRef]

12. $\mathrm{Ng} C S$, Watson CJ, Palmer CR, See TC, Beharry NA, Houdsen BA, et al. Evaluation of early abdominopelvic computed tomography in patients with acute abdominal pain of unknown cause: prospective randomised study. BMJ 2002; 325: 1387-90. [CrossRef]

13. Weiner JB, Nagurney JT, Brown DF, Sane S, Wang AC. Duration of symptoms and follow-up patterns of patients discharged from the emergency department after presenting with abdominal or flank pain. Fam Pract 2004; 21:314-6. [CrossRef]

14. Onur OE, Guneysel O, Unluer EE, Akaoğlu H, Çingi A, Onur E, et al. “Outpatient follow-up" or "Active clinical observation" in patients with nonspecific abdominal pain in the Emergency Department. A randomized clinical trial. Minevra Chir 2008; 63: 9-15.

15. Pines JM, Griffey RT. What We have learned from a decade of ED crowding research. Acad Emerg Med 2015; 22: 985-7. [CrossRef]

16. Marino PA, Mays AC, Thompson EJ. Bypass rapid assessment triage: How culture change improved One emergency Department's safety, throughput and patient satisfaction. J Emerg Nurs 2015; 41:213-20. [CrossRef]

17. Stang AS, Crotts J, Johnson DW, Hartling L, Guttmann A. Crowding measures associated with the quality of emergency department care: a systematic review. Acad Emerg Med 2015; 22: 643-56. [CrossRef]

18. Liu JLY, Wyatt JC, Deeks JJ, Clamp S, Keen J, Verde P, et al. Chapter 1. Background to study. In Systematic reviews of clinical decision toos for acute abdominal pain. Health Technology Assesment 2006; 10: 1-8.

19. Korner H, Sondenaa K, Soreide JA, Andersen E, Nysted A, Lende TH. Structured data collection improves the diagnosis of acute appendicitis. $\mathrm{Br} J$ Surg 1998; 85: 341-4. [CrossRef]

20. Mulvehill S, Schneider G, Cullen CM, Roaten S, Foster B, Porter A. Template-guided versus undirected written medical documentation: a prospective, randomized trial in a family medicine residency clinic. J Am Board Fam Pract 2005; 18: 464-9. [CrossRef] 